\title{
GLAUCOMA EXPERIMENTAL NO CÃO
}

\author{
EXPERIMENTAL GLAUCOMA IN THE DOG
}

Puulo Sérglo de Moraes BARROS'; Mlguel Noed Nencenteo EURNIRR JUNIOR;

Slivia Berlanga de Moracs BARROS'; Jose Rkerdo Lima REHDER²

\begin{abstract}
RESUMO
O glaucoma experimental foi produzido $\mathrm{cm}$ animais como coelho e macaco na tentativa de explicar os mecanismos da doença. Modelos de glaucoma espontanco também foram descritos. No presente trabalho a elevaçăo da pressăo intraocular (PIO) foi produzida em 12 cảes por hemÁcia autóloga fixada em glutaraldcído injetada na câmara anterior do olho esquerdo, sob microscópio cirúrgico. O olho direito foi o controle. Tonometria pelo Schiou foi realizada a cada 24 horas com o animal em posiçăo sentada. Com intervalos de tempo que variavam de 2 a 20 dias apos a injoçao os animais foram sacrificados, os olhos enucleados c congclados, medidos os diametros sagital e transversal e entảo fixados em soluçæo de formol a $10 \%$ c os cortes corados pela hemaloxilinacosina para exame histológico. Em todos os animais a PIO foi maior quando comparado com on controles, o mesmo acontecendo com a medida dos diâmctros que foram também maiores. O achados histológicos foram compativeis com glaucoma.
\end{abstract}

UNITERMOS: Glaucoma; Caes

\section{INTRODUÇĀO}

Muitos dos conhecimentos das doenças dos olhos do homem advêm de modelos experimentais em animais. Embora existam diferenças anatomicas e fisiologicas entre o homem e as diferentes especies animais, muitas das afecçסes oculares se processam de maneira similar, senăo idêntica, fazendo dos modelos experimentais em animais, meio de real valor na elucidaçăo de vários problemas. O glaucoma - aumento patológico da pressão intraocular (IOP) - é importante afecçăo do olho humano. Dentre os animais, o căo e o que apresenta maior incidencia do glaucoma, particularmente em determinadas raças (GELATT", 1981). As manifestaçðes oculares do glaucoma săo dependentes do tempo de evoluçăo, duraçăo e magnitude da elevaçåo da IOP. Animais jovens rapidamente desenvolvem buftalmia que tende a proteger a retina e o disco óptico dos aumentos de IOP por periodo de tempo curto. Uma elevaçăo crônica da IOP no căo pode ser tolerada por um período de tempo devido a buftalmia e as alteraçoes compensatórias que o olho pode apresentar durante este tempo. Elevaçoes agudas acentuadas da IOP podem rapidamente produzir alterafóes no globo ocular (GELATT*, 1981).

O glaucoma experimentalmente induzido tem sido descnvolvido para estudar os efeitos da elevaço da IOP nos tecidos oculares, determinar a eficácia de medicamentos e/ou de tratamentos cirúrgicos na reduçáo da IOP bem como os mecanismos de produça do glaucoma.

HUGGERT (1957) conseguiu bloquear a drenagem de humor aquoso $\mathrm{cm}$ coelhos mas com aumento năo significativo da IOP, enquanto KUPFER' (1962) obleve hipenens\$o intraocular cm coelhos introduzindo tubo de polietileno no angulo de drenagem da câmara anterior.

CARVALHO (1962) injetando fragmentos de algodso na camara anterior de coelhos elevou a IOP para $38-40 \mathrm{mmHg}$; nos animais en que o glaucoma persistu por mais de 30 dias realizou estudo da retina e disco optico. KALVIN et al.' (1966) produziu IOP elevada em macacos com injeçăo intraocular de talco ou cimento dentário.

A injeção de alfa-quimotripsina nos olhos pode produzir aumento favorável da IOP. Esta enzima dissolve a zonula do cristalino e estes fragmentos văo obstruir a malha do trabeculado. Esta técnica tem sido utilizada em primatas para estudo de alteraçoes do nervo óptico e alteraçoes vasculares (LESSEL; KUWABARA*, 1969). Elevaçao aguda da IOP menor que $10 \mathrm{mmHg}$ foi observada $\mathrm{cm}$ cles por BARRIE et al.' (1982) após injeçăo de 500 a 750 unidades de alfaquimotripsina. A ciclocrioterapia causa uma elevaço aguda da IOP em macaco Rhesus, tendo sido utilizada por MINCKLER et al. ${ }^{12}$ (1976) para estudar o transporte axoplasmático de células ganglionares e posteriormente MINCKLER et al."(1977) para o controle da elevacaso da IOP usando técnica de canulaça e perfus"o.

O "Laser" de argónio foi utilizado por GAASTERLAND c KUPFER' (1974) que obtiveram reduçlo da drenagem do humor aquoso, por fotocoagulaçăo repetida do ângulo iridocomeano.

1- Professor Associado - Faculdade de Medicina Veteriníria e Zootecnia da USP

2- Profeseor Adjunto - Escola Paulisu de Medicina

3. Professor Associado - Faculdade de Ciencias Farmactuticas da USP 
QUIGLEY e ADDICKS ${ }^{14}$ (1980) descreveram um método para a produção experimental de glaucoma $\mathrm{cm}$ macacos pela injeçăo, na câmara anterior, de hemácias autólogas fixadas $\mathrm{em}$ glutaraldeído. Em 1985, REHDER's modificou a técnica de Quigley e Addicks obtendo aumento constante e duradouro da pressão intraocular em coclhos.

Com excę̧a dos modelos de glaucoma espontânco descrito em caes da raça Beagle (GELATT et al.', 1981) nenhum outro método foi até agora proposto para induzir expcrimentalmente glaucoma em căes. A ausência deste modclo no căo impossibilitou até o momento o estabclecimento dos padrós de lesoes das estruturas do globo ocular frente a clevaçðes da pressấ intraocular năo so quanto à intensidadc como quanto à duraçăo do glaucoma.

Deste modo, propomo-nos a desenvolver ténica para o estabelecimento de glaucoma experimental no căo.

\section{MATERIAL F MÉTODO}

Foram utilizados 12 animais da especic canina, 9 machos $\mathrm{c} 3$ femeas, sem raça defínida, adultos com idades variadas, pesando entre 8 e $12 \mathrm{~kg}$, clinicamente sadios.

Tonometria por indentaça de ambos os olhos foi rcalizada com o tonometro de Schiót ${ }^{*}$, utilizando-se a tabela de calibraço preconizada por PEIFFER JÚNIOR et al. ${ }^{13}(1977)$, antes e após a injeçăo de hemácias fixadas, com o animal cm posiçăo sentada, com o intervalo de 24 horas nas duas primeiras semanas e com intervalo de 7 dias até que a pressào intraocular (IOP) nåo mais fosse possível ser medida face a alteraçies da cómea.

Exame oftalmológico foi efetuado com o auxilio de lupa c foco de luz e biomicroscópio com lampada de fenda**.

\section{Preparo das Hemácias}

O sangue autólogo foi obtido da veia jugular $\mathrm{cm}$ scringa heparinizada. Uma mistura de sangue total e sacarose $0,25 \mathrm{M}$. na proporça de 1:4, foi centrifugada durante 15 minutos a $1000 \mathrm{rpm}$. O precipitado contendo as hemácias foi ressuspenso $\mathrm{cm}$ sacarose $0,25 \mathrm{M}$ na proporçăo de 1:4 c a centrifugaçăo repetida. As hemácias foram então fixadas com 10 vezcs seu volume com soluçào de glutaraldeído $5 \% \mathrm{~cm}$ tampao fosfato pH 7.0 por uma hora. Após centrifugação as hemácias foram lavadas 7 vezes em salina $0,9 \%$ estéril para remoçăo do fixador. As hemácias foram ressuspensas $\mathrm{cm}$ igual volume de soluçâo de cloreto de sódio $0,9 \%$ estéril $e$ assim utilizadas.

\section{Injeçảo Intracamerular de Hemácias}

Foi realizada a injecăo de $0,5 \mathrm{ml}$ da suspensło de hemácias fixadas na câmara anterior através de paracentese do olho esquerdo, sob microscópio cirúrgico***, permanecendo o olho dircito como controle.

- Tonometro de indentę̧lo - Riester - West Germany

* LF-M2 - D.F. Vasconoellow

$\cdots$ MC M9 - D.F. Vasconcellos (auxflio CNPq- Proc. 403412/34)
Para testar a inoquidade da soluçă usada para ressuspender as hemácias, injetamos $0,5 \mathrm{ml}$ do sobrenadance da soluçato de hemácias, obtida por decantaçăo, na câmara anterior do olho direito de 2 animais.

\section{Medida dos Dismetros Oculares}

Após o sacrifício, ambos os olhos foram cnucleados e congelados, c os diâmetros transversal e sagital medidos.

As variaçơs dos diâmetros foram analisadas estatisticamente aplicando-se o teste " $\mathrm{t}$ " de Student, considerando-se o nivel de significância de $5 \%$.

\section{Exame HistopatoKgico}

Os olhos foram fixados em formol 10\% tamponado, $\mathrm{pH} 7,0$, por período de 48 horas, desidratados e incluídos $\mathrm{cm}$ parafine Cortes de $4 \mu$ de espessura foram corados pela hematoxilin. eosina.

\section{RESULTADOS}

As medidas da pressăo intraocular (IOP) estăo aprescntadas nas Fig. 1,2 e 3 . O máximo IOP oblida foi de $88,3 \mathrm{~mm}$ de $\mathrm{H}_{\mathrm{g}}$. Todos os animais desenvolveram aumento de IOP a parir de 24 horas após a injeçăo de hemácias fixadas e esta se mante. ve por no mínino 5 dias e no máximo de 21 dias (lempo máximo de observaçăo).

As medidas dos diâmetros sagital e transversal cstăo represcntadas na Tab. 1. Estes sofreram aumentos de 2 a $8.5 \mathrm{~mm}$ (sagital) e 1 a $4 \mathrm{~mm}$ (transversal). Quando colejados seus valores com os dos olhos controle, constatamos que houve aumento estatisticamente significante ao nível de $5 \%$.

Os achados anátomo-patológicos incluíram: a) Hemácias na cåmara anterior; b) Catarata e aumento da profundidade do câmara antcrior; c) Vacuolização das células cpitcliais pigmentadas do corpo ciliar; d) Descolamento sctorial da retina desorganizada com perda de células ganglionares.

\section{DISCUSSÃO E CONCLUSÓES}

O cslabclocimento do glaucoma experimental no calo ainda nao foi retatado na literatura, embora tal patologia seja ainda um desafío, năo só para a medicina humana como para a veterinária, constituindo, seu estudo, imporiante meta de verrios centros de pesquisa.

No presente trabalho descrevemos um modelo experiments para produçấo de glaucoma no căo através de método jâ des. crito $\mathrm{cm}$ outras espécies como o macaco (QUIGLEY; ADDICKS $\left.^{14}, 1980\right)$ e o coelho (REHDER ${ }^{13}, 1985$ ).

Embora năo tenha sido possível medir adequadamente a pressőes intraoculares por muitos dias, pois a alteraç3 comeana foi de tal monta que a tonometria de indentacáo nito foi capaz de, aposs o prazo máximo de 21 dias, ser realizade obuivemos resultados de aumento de pressato compativeis com 
BARROS, P.S.M.; BRUNIER JÚNIOR, M.N.N.; BARROS, S.B.M.; RIiIIDFR, J.R.L. Glaucoma experimental no clo. Braz. J. vet. Rea. anlm. Sd., Sto Paulo, v.30, n.1. p. 33-8, 1993.

TABELA 1

Medidas dos diâmetros sagital e transversal em milímetros, dos olhos direito (OD) (controle) e esquerdo (OE) (experimental) com suas médias e desvios padrōes. Såo Paulo, 1992.

\begin{tabular}{|c|c|c|c|c|c|c|}
\hline \multirow[b]{2}{*}{$N^{\circ}$ do Animal } & \multicolumn{3}{|c|}{ Diâmetro Sagital } & \multicolumn{3}{|c|}{ Diamcuro Transveral } \\
\hline & O.D. & O.E. & Diferença & O.D. & O.E. & Difcrenç: \\
\hline $\begin{array}{l}01 \\
02 \\
03 \\
04 \\
05 \\
06 \\
07 \\
08 \\
09 \\
10 \\
11 \\
12\end{array}$ & $\begin{array}{l}21 \\
23 \\
22,5 \\
22,5 \\
22 \\
21 \\
21 \\
21 \\
21,5 \\
21 \\
20 \\
20\end{array}$ & $\begin{array}{l}24 \\
25 \\
31 \\
27,5 \\
28 \\
29 \\
26,5 \\
29 \\
25 \\
28 \\
23 \\
24\end{array}$ & $\begin{array}{l}4 \\
2 \\
8,5 \\
5 \\
6 \\
8 \\
5,5 \\
8 \\
4,5 \\
7 \\
3 \\
4 \\
\end{array}$ & $\begin{array}{l}21,5 \\
23 \\
23 \\
22 \\
22 \\
21,5 \\
22 \\
21 \\
21 \\
22 \\
20 \\
20\end{array}$ & $\begin{array}{l}23 \\
24 \\
26,5 \\
26 \\
24 \\
24 \\
25 \\
24 \\
22,5 \\
24,5 \\
23 \\
22\end{array}$ & $\begin{array}{l}1,5 \\
1 \\
3,5 \\
4 \\
2 \\
2,5 \\
3 \\
3 \\
1,5 \\
2,5 \\
3 \\
2\end{array}$ \\
\hline \multirow[t]{2}{*}{$x \pm s$} & $21,4 \pm 1,0$ & $26,8 \pm 2,4$ & $5,5 \pm 2,1$ & $21,6 \pm 1,0$ & $24,0 \pm 1,3$ & $2,5 \pm 0,9$ \\
\hline & \multicolumn{3}{|c|}{$\begin{array}{c}\% \text { de aumento } \\
25,5 \%\end{array}$} & \multicolumn{3}{|c|}{$\begin{array}{c}\% \text { de aumento } \\
11,4 \%\end{array}$} \\
\hline
\end{tabular}

$S=$ desvio padrao

ayueles achados em cáes com glaucoma clínico. Tal modclo se presta principalmente ao estudo do glaucoma agudo por obstruça do trabeculado, uma vez que todos os animais apresentavam aumento da pressăo intraocular após 24 horas da injecă intracamerular de hemácias fixadas.

Os diâmetros tanto sagital quanto transversal aumentados sāo compatuveis com o que ocorre normalmente no curso do glaucoma no căo, por peculiaridade da estrutura da esclera, à semelhança do que ocorre nas crianças, cm que a buftalmia é achado frequente (MAGRANE ${ }^{10}, 1957$ ).

Os æchados anátomo-patológicos se relacionam com os sinais clínicos observados nos diferentes căes. As hemácias lixadas contidas na câmara anterior demonstram que estas năo săo drenadas rapidamente, al permanecendo por período de tempo por nós năo determinado, provavelmente obstruindo o ângulo iridocorneano.

A catarata observada macro e microscopicamente denota alteraçáo do metabolismo do epitćlio da cápsula anterior, o que esperado quando se aumenta a tensăo intraocular.

Uma cåmara anterior mais profunda com abaulamento posterior da íris ocorre $\mathrm{em}$ consequência da estagnaçăo do humor aquoso nas câmaras, uma vez que este nato consegue atravessar o trabeculado e ganhar o plexo venoso da csclera. Um achado na explicado foi a vacuolizaçāo das células epilcliais do corpo ciliar embora sendo encontro frequente e relatado nos tratados de patologia $\propto$ cular.

A escavaça do disco óptico, achado auxiliar no diagnóstico do glaucoma, foi alteracăo encontrada em todos os animais, bem como gliose do nervo óptico, desorganizaçăo da retina c perda das células ganglionares.

Podemos concluir que a injeço intracamerular de hemácias fixades constitui modelo experimental, embora limilado, de produçẩo de glaucoma no căo e que poderá levar à luz conhecimentos da ctiopatogenia e fisiopatologia desta docnça que aflige nāo só os animais como o próprio homem.

\section{SUMMARY}

Experimental glaucoma was produced in rabbits and monkeys as an effort to explain the mechanisms of this discase. Spontancous animal model of glaucoma has also been used. Many tochnics were employed to produce chronic intraocular pression (IOP) elevation. Fixed autologous red blood cells were used to produce elevated IOP in rabbits and monkeys. In this paper we present the results of the elevation of the KP in 12 mongrel dogs injecting autologous red blood cells (RBC) fixed in 5\% glutaraldehyde in phosphate buffer pH 7.0. The RBC were injected into the left cye following paracentesis and under surgical microscope. The right eyes were controls. Schiotz tonometry was performed, each 24 hours, with the dog in the siuting position. The calibration table Schiolz conomery in dogs from PEIFFER JUNIOR et al. ${ }^{13}$ (1977) was used. The cnucleated eyes were freczed and measured the sagittal and transversal diameters. The cyes were fixed in 10\% formalin and sections were stained with hematoxilin-eosin for histological examination. The fixed $\mathrm{RBC}$ injected into the anterior chamber produced elevation in the IOP with buphthalmus and keratitis. The IOP was increased in all dogs when compared with the controls, the same occured with the cyes diameters. The pathologic findings were suggestive of glaucoma.

UNITFRMS: Glaucoma; Dogs

\section{REFERENCIAS BIBLIOGRÁFICAS}

01-BARRIE, K.P.; GELATT, K.N.; GUM, G.G.; SAMUELSON, D.A. Effects of alpha chymorypain on the canine eye. Amer. J. vet. Res, v. 113, p. 207-16, 1982. 
02-CARVALHO, C.A. Histopathology of the retin and optic nerve with experimental glaucoma. Arch. Ophthal., v. 67, p. 123. 6. 1962.

03-GAASTERLAND, D.; KUPFER, C. Experimental glaucoma in the rhesus monkey. Invest. Ophthal., v.13, p. 455-7, 1974

04-GELATT, K.N. The canine glaucomas. In: GELATT, K.N., cd. Textbook of veterinary ophthaimology. Philadelphia, Lea \& Fobiger, 1981. p. 390.

05-GELATT, K.N., GUM, G.G.; GWIN, R.M.; BROMBERG, N.M.; MERIDETH, R.E.; SAMUELSON, D.A. Animal model of humen disease. Primary open angle glaucoma. Inheriled primary open angle glaucoma in the Beagle. Amer. J. Path., v.102, p. 292-5, 1981.

06-HUGGERT, A. Obstruction of the outhow of squeous humor produced experimentally. Acta Ophthal., v. 35, p. 1-11, 1957.

07-KALVIN, N.H.; HAMASAKI, D.I.; GASS, J.D.M. Experimental glaucoma in monkeys. II. Studies of intraocular vascularity during glaucoma. Arch. Ophthal., v. 76; p. 82-94, 1966.

08-KUPFER, C. Studies of intraocular pressure. II. The histopethology of experimentally increased intraccular pressure in the rabbit. Invest. Ophthal., v.1. p. 445-79, 1962.

09-LESSEL, S.; KUWABARA, T. Experimental alpha-chymotrypsin glaucome. Arch. Ophthal., v. 81, p. 853-69, 1969.
10-MAGRANE, W.G. Canine glaucoma. I. Methode of diagnosis. J. Amer. Vet. Med. As., v. 131, p. 311 4, 1957.

11- MINCKLER, D.S.; BUNT, A.J.; ЮHANSON, G.W. Orthogrede and retrograde axoplasmic transpor during acute ocular hypertension in the monkey. Invest. OphthaL. Vloual SeL. v. 16. p. $426-41,1977$.

12-MINCKLER, D.S.; TSO, M.O.M.; ZIMMERMAN, L.E. A light microscopic autoradiographic study of axoplasmic transpon in the optic nerve head during ocular hypotomy, increased intraocular pressure and papilledema. Amer. J. Ophthal., v. 82, p. 741-57, 1976.

13 PEIFFER JÚNIOR, R.L.; GELATT, K.N.; JESSEN, C.R.; GUM, G.G.; GWIN, R.R.; DAVIS, J. Calibration of the Schicuz tonomeler of the normal canine eye. Amer. J. vet. Res, v. 38, p. 1881-9, 1977.

14.QUIGLEY, H.A.; ADDICKS. E.M. Choronic experimental glaucoma in primates. I. Production of elevated intracular pressure by anterior chamber injection of autologous ghost red bloods cells. Invest. Ophthal. Vlsual Scl., v. 19. p. 126-36, 1980.

15- REIDER, J.R.C.L. Método simplificado para o desenvolvimento do glaucomn experimental. Arq. bres. Oftalm., v. 48, p. 6 . 8. 1985.

Recebido pera publicaçlo em 05/06/92 Aprovedo para publiceçlo em 15/12/92 

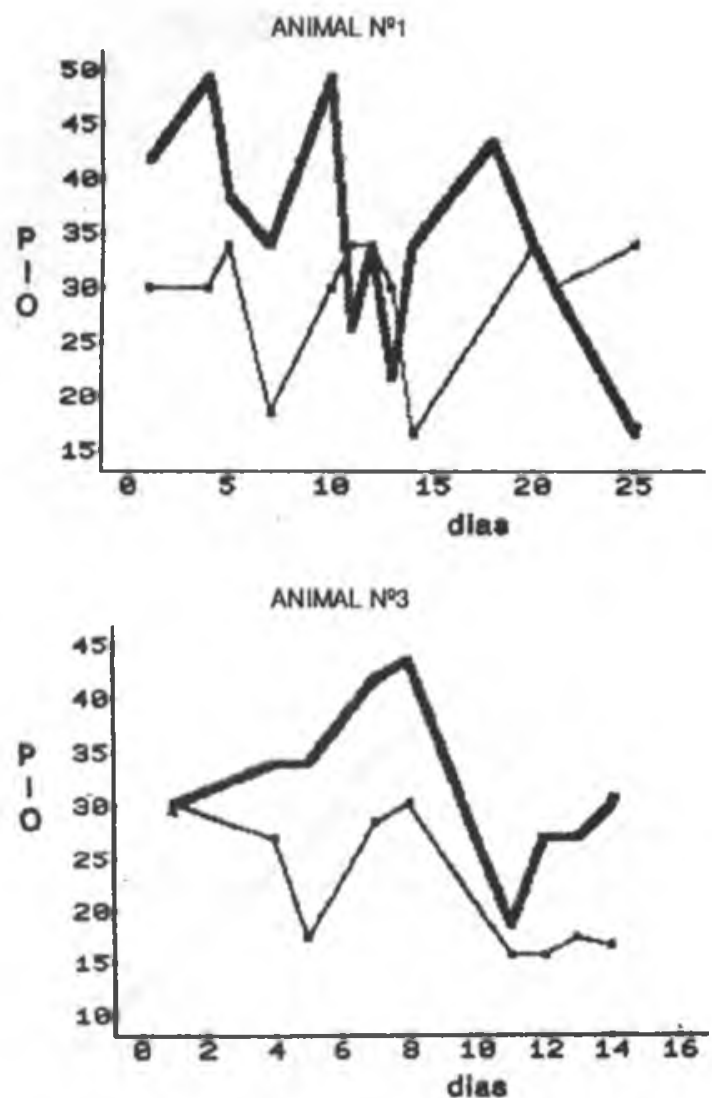

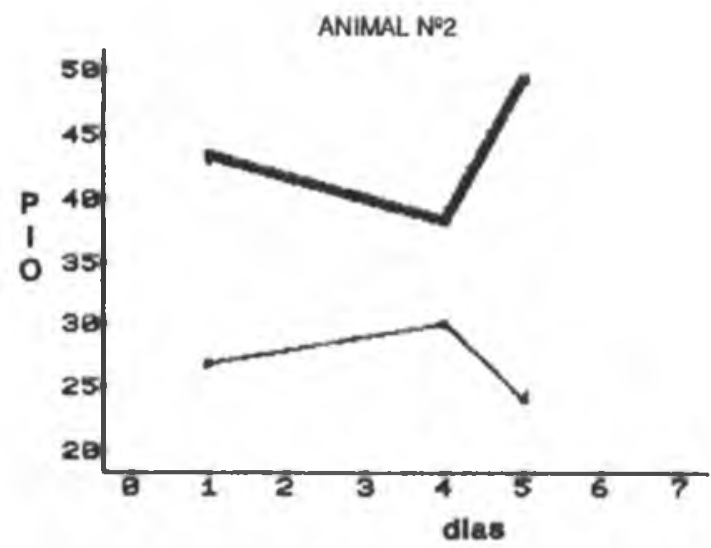

ANIMAL. N ${ }^{2} 4$

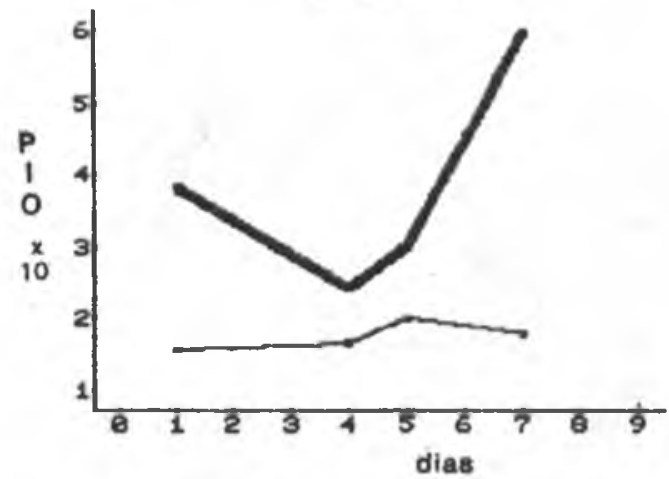

FIGURA 1

Gráficos dos valores das pressōes intraoculares (PIO), em mm de $\mathrm{Hg}$, dos animais 1 a 4 .

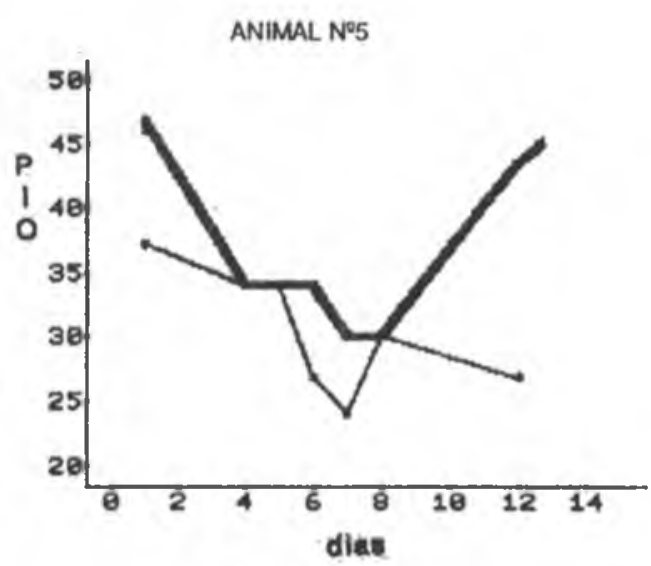

ANIMAL N07

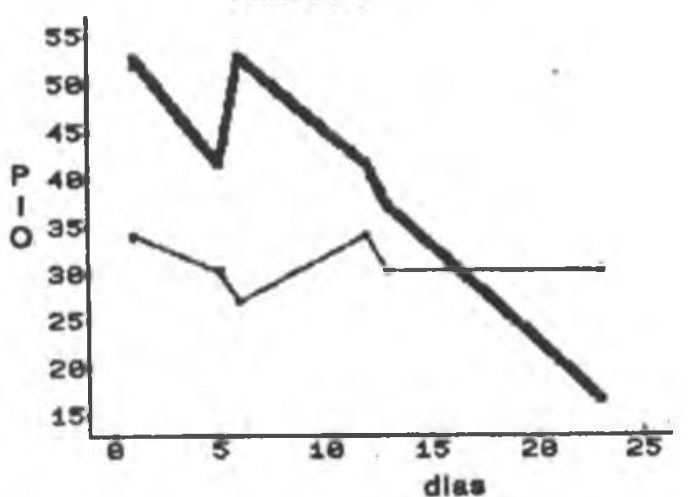

ANIMAL N'6

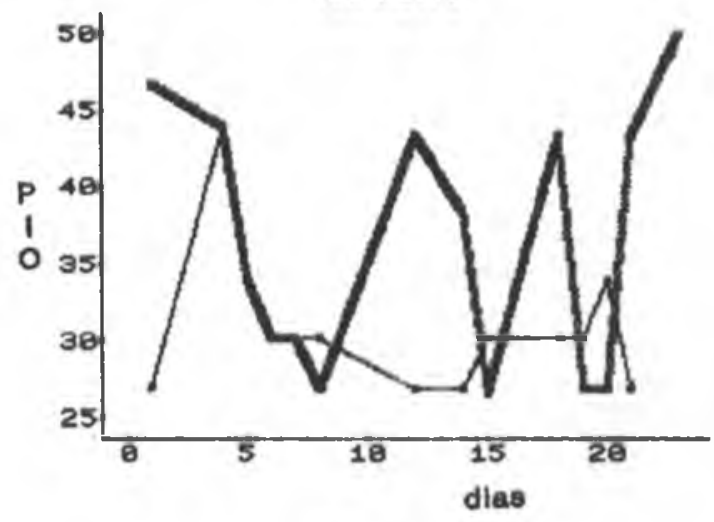

ANIMAL NOB

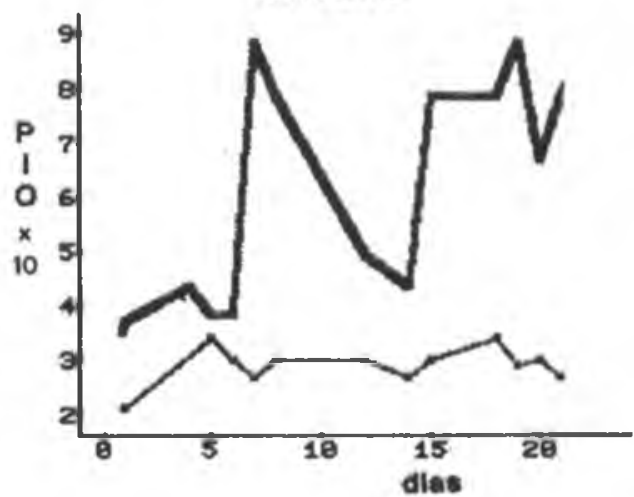

FIGURA 2

Gráficos dos valores das pressð̋es inıraoculares (PIO), $\mathrm{cm}$ mm de $\mathrm{Hg}$, dos animais 5 a 8 . 
O gráfico do Animal n 7, Figura 2, p.37, v.30, n.1, 1993, deverá ser substituído por:

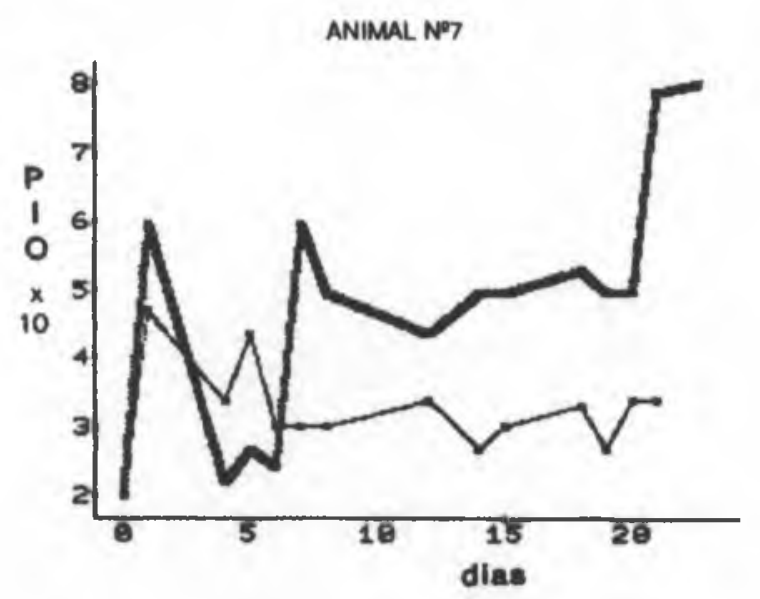




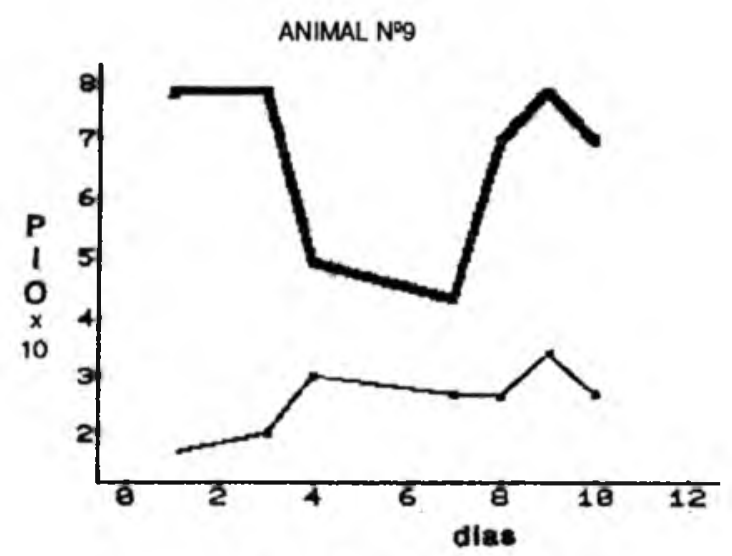

ANIMAL N $N^{0} 11$

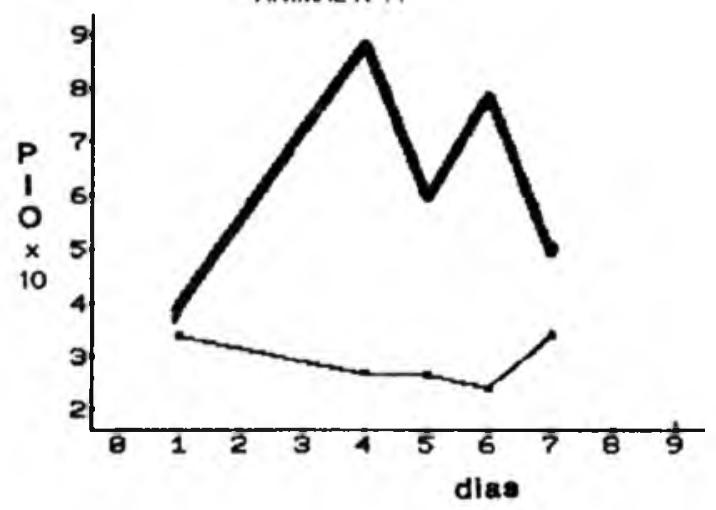

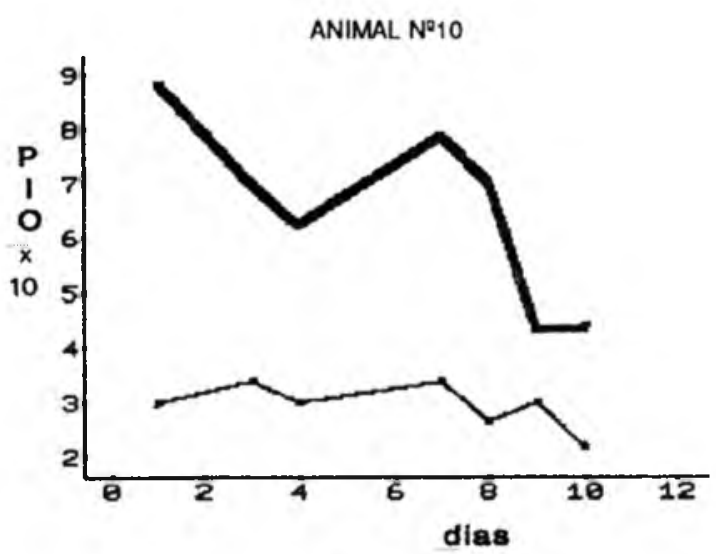

ANIMAL No12

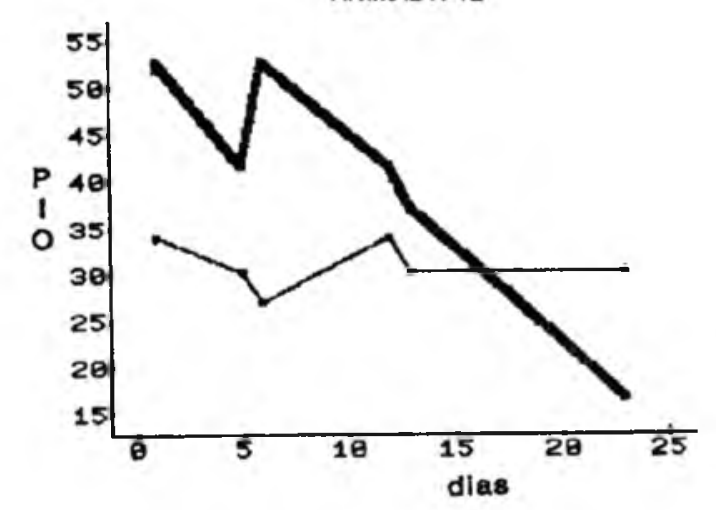

FIGURA 3

Gráficos dos valores das pressōes intraoculares (PIO), $\mathrm{cm} \mathrm{mm} \mathrm{de} \mathrm{Hg}$, dos animais 9 a 12 . 